\title{
Actuarial Adjustment Aspects of Public Pension Schemes
}

\author{
Kamil Galuščák* \\ CERGE-EI, Politických vezňů 7, 11121 Prague, Czech Republic \\ E-mail: kamil.galuscak@cerge.cuni.cz, galuscak@volny.cz
}

May 2000

\begin{abstract}
It has been shown in economic research that public pay-as-you-go definedbenefit pension plans penalize those who continue to work beyond a certain age by reducing the present discounted value of future retirement benefits. In discussions on the effectiveness of policies aimed at eliminating this age-dependency in worker retirement decisions, it is often assumed either that the benefits in all future periods have the same weight in the present discounted value or that the discount rate is close to unity due to low real interest rates used in this case. In this paper we show, using the example of the U.S. pension scheme, that discounting plays a crucial role, since the formula for the present discounted value of future retirement benefits is sensitive to the discount rate used. Using discount rates derived from real interest rates in 1997, we find that the annual delayed retirement credit by which retirement benefits should be increased to compensate for lost benefits is at least $25 \%$ greater than it is in the case when discounting is neglected. Moreover when accouting for risk aversion towards lifetime uncertainty, the optimal delayed retirement credit is increased by $15-25 \%$. Our results indicate that the U.S. pension scheme is not age neutral between ages 62 and 65. This may explain the peak in labor force withdrawal observed at age 62 .
\end{abstract}

*I would like to thank Randall Filer, Jan Kmenta, Stepan Jurajda, and Petr Duczynski for their helpful comments and suggestions. A part of this work was supported by the Research Support Scheme of the Open Society Support Foundation, grant No. 133/1998. I remain responsible for all errors and interpretations. 


\section{Introduction}

The labor market behavior of older workers is attracting the attention of many economists now that policies aimed at affecting such behavior have become an important part of policy-related debates. Declining labor force participation in the postwar U.S. economy (Peracchi and Welch, 1994) and in other developed ecomomies, along with increasing life expectancy, have caused fiscal tensions in financing public pensions. ${ }^{1}$ In order to combat these difficulties, policies to increase labor force participation of older workers and to encourage late retirement have been introduced in the last two decades. ${ }^{2}$ Recent evidence on the labor market behavior of older workers in the U.S. and some other OECD countries (Smeeding and Quinn, 1997) has shown that the downward trend in their labor force participation stopped in the mid-1980s and that even a slight increase was observed thereafter. This has revived discussions about the effectiveness of pro-work policies.

Economic research has shown that public pay-as-you-go defined-benefit (DB) pension plans in which the amount of the benefit is determined by wages in the few years prior to retirement and the number of years of contributing to the pension plan have important retirement incentives or disincentives beyond a certain age (Stock and Wise, 1990). Many DB plans penalize workers who continue working beyond a certain age by reducing the present discounted value of their future retirement benefits. Pro-work policies, however, incorporate changes which eliminate these incentives to retire and may even introduce an additional incentive to stay in the labor market. The parameter of interest here is the actuarial adjustment rate at which the unpaid benefits of an individual who is eligible for and does not receive a pension are compensated in the future. The idea is to keep the present discounted value of future retirement benefits the same, eliminating its dependency on the age of retirement.

The relation between discount rates and real interest rates can be explained both by investing and borrowing in capital markets. ${ }^{3}$ Assume the length of life is known. When real interest rates $r$ are zero or negative, the discount rate $\beta$ equals or is greater than unity, such that $\beta=1 /(1+r)$. If there are positive real

\footnotetext{
${ }^{1}$ World Bank Report (1994) describes potential problems of the ageing population in the world-wide context and presents proposals to reform pension systems.

${ }^{2}$ For an overview of these policies introduced in the U.S., see Burkhauser and Quinn (1997).

${ }^{3}$ Investing in capital markets means lending available financial sources by individuals in the form of deposits, for example. Borrowing, on the other hand, takes the form of loans and credits.
} 
interest rates, individuals may prefer to have access to their financial sources in the current time period rather than in the future, and earn the real interest rate. The discount rate at which future retirement benefits are evaluated falls below unity in this case. We may conclude that retirement is less likely to be delayed when high positive real interest rates are observed. An alternative explanation of the relation between discount rates and real interest rates comes from the side of borrowing. An individual may choose to postpone retirement and borrow in capital markets to achieve his desired financial path. The rate at which future retirement benefits are discounted is determined by real interest rates on borrowing in this case. Higher real interest rates on borrowing decrease the willingness to delay retirement.

These two explanations rely on three assumptions. Firstly, there are no fixed costs of work so that a worker can freely choose the labor supply. Secondly, there are no constraints on borrowing and lending such that a worker is able to achieve the desired financial path in capital markets, and finally, retirement benefits are indexed to inflation. Both the explanations provide the same predictions on the size of the discount rate if real interest rates on borrowing and lending are the same.

Based on these assumptions, we may evaluate the costs and benefits of introducing a policy that removes the age dependency of the actuarial adjustment. Suppose that there is a disincentive to retire beyond a certain age such that all workers retire at that age. Suppose further that a delayed retirement credit such that the present discounted value of future retirement benefits does not depend on the age of retirement is introduced. In this case, there are no additional costs to introducing this policy. In fact, the increased labor supply raises tax revenues from additonal work as well as state revenues from the social security insurance payments. This implies that such a pro-work policy should have favorable advantages for the state financing of pensions.

The example given above does not account for post-retirement work. If a pensioner works, constraints on eligibility for retirement benefits are often imposed, for example limits on earnings (the earnings test). In this case, benefits are not paid if the income from post-retirement work exceeds a certain limit. Future retirement benefits are then increased to compensate for the unpaid benefits. The earnings test is in this way similar to late retirement. If the compensation credit is high enough such that the present discounted value of future retirement benefits is the same, no change in the labor supply is expected when the earnings test is introduced.

In this paper we introduce risk aversion in the utility of lifetime and find that 
the effective time horizon is shorter for risk averse than for risk neutral individuals. Using the example of the U.S. pension scheme we show that discounting plays a crucial role since the formula for the delayed retirement credit by which future benefits are increased in the case of late retirement is sensitive to the discount rate used. Finally, we compute the optimal values of the delayed retirement credit for particular parameters in the case of risk neutrality and in the case of risk aversion.

The paper is organized as follows. Section 2 provides a brief overview of the literature on this topic. The next section analyzes the actuarial adjustment mechanism and introduces risk aversion. The optimal parameters in the cases of risk neutrality and risk aversion are found using the example of the U.S. pension system in Section 4. The last section assesses policy-related findings and concludes the study.

\section{Survey of Literature}

Although the age-neutral pension rule should not in theory affect the labor supply of older workers, numerous studies provide evidence to the contrary. The U.S. pension scheme is age neutral between ages 62 and $65,{ }^{4}$ but a peak in the labor force withdrawal at the age 62 is still observed (Blau, 1994). Explanations of this phenomenon called "the retirement puzzle" either rely on liquidity constraints (Kahn, 1988, Rust and Phelan, 1997) or provide evidence that a lack of part-time jobs and the fixed costs of work are responsible for the withdrawal from the labor market (Hurd, 1996). Other studies provide evidence that the worker's perception of the adjustment mechanism is responsible for the labor force withdrawal. Thus, Burtless and Moffitt (1985) conclude that the adjustment rule for the foregone benefits is widely unrecognized. Reimers and Honig (1993) investigate the role of time preferences in the labor supply when the earnings test is in effect. They show that the effective time horizon is crucial in the labor supply decisions of older workers. They also find significant differences between male and female labor supply responses to the earnings test rule.

Whitehouse (1990) analyzes the removal of the earnings test in the United Kingdom in 1989. He finds that the compensation for unpaid benefits in the cases of late retirement and the earnings test is fair for women, but not for men

\footnotetext{
${ }^{4}$ The actuarial increase in retirement benefits is $8 \%$ per year between ages 62 and 65 , and was $3 \%$ per year between ages 65 and 70 prior to 1990 . According to the 1983 amendments to the Social Security Act, beginning in 1990 the actuarial increase has been gradually raised and will reach $8 \%$ per year by 2008. See, for example, Reimers and Honig (1993) for details.
} 
because the official retirement age is lower for females than for males, while women live longer than men in the U.K. His calculations are based on assumptions that there is no discounting of future retirement benefits, and that lifetime equals life expectancy.

Attention should be devoted to questions related to discount rates and time preferences. ${ }^{5}$ In maximization problems of time separable utility functions of consumption, subjective time discount rates have traditionally been less than unity in life cycle models with certain or uncertain lifetimes. However, in an overlapping setting there are no restrictions on the size of the rate of time preferences. For example, Kocherlakota (1990) shows that equilibria with positive interest rates exist in infinite horizon growth economies in which per capita consumption grows over time. In these economies, individuals prefer consuming today rather than in the future, even though the subjective time discount rate is larger than one.

The empirical evidence suggests that a subjective time discount rate greater than unity is plausible. Imrohoroglu, et al. (1998) provide an instructive overview of this topic. Incorporating mortality risk into a life cycle model and assuming an interest rate of 0.03, Hurd's (1989) nonlinear 2SLS estimates using panel data from the Retirement History Survey deliver a subjective time discount rate of 1.011. Hurd (1989) also discusses the relation between subjective time discount rates $\rho$ and discount rates $\beta$ derived from real interest rates. Although it is possible to claim that $\rho<\beta$, some studies of growth models imply that $\rho>\beta$ (see for example Kocherlakota, 1990, or Hurd, 1989).

Lifetime uncertainty has been introduced in life cycle models to reconcile the fact observed in cross sections that the elderly seem not to dissave at advanced ages. In his pioneering contribution Yaari (1965) finds that in an economy without social security annuities, the future is discounted more heavily than it would be with a certain lifetime if the marginal utility of consumption exceeds the marginal utility of bequests, while bequests are accidental due to the uncertainty of survival. The introduction of annuities is equivalent to the removal of lifetime uncertainty. However, lifetime uncertainty is important when evaluating the efficiency of the actuarial adjustment in the pension scheme, since the length of the period over which adjusted retirement benefits are received is crucial in assessing the efficiency of the adjustment mechanism.

\footnotetext{
${ }^{5}$ The difference between time preferences and discount rates is described in Hurd (1989). Time preferences enter the utility maximization problem, while discount rates $\beta$ derived from real interest rates as $\beta=1 /(1+r)$ are implemented in the budget constraint.
} 


\section{Analysis of the Actuarial Adjustment}

As we mentioned in Section 2, defined-benefit pension plans may have incentive or disincentive effects on workers' decisions to retire. The particular situation depends on the parameters of the pension scheme. In this section we analyze the impact of these parameters on the fairness of actuarial adjustment in the cases of late retirement and the earnings test. We introduce a general formula for adjusting the future benefits and analyze the implicit function for the optimal delayed retirement credit in the case of certain lifetime. We then model uncertain lifetime by introducing the risk premium into the utility associated with the length of life. We assess how the risk aversion to uncertain lifetime affects the individual effective time horizon.

\subsection{General Framework}

Suppose a worker is eligible for retirement benefits $B\left(R_{0}\right)$ at the lowest retirement age $R_{0}{ }^{6}$ If the worker retires at age $R$, such that $R>R_{0}$, he receives benefits $B(R)$, such that $B(R)>B\left(R_{0}\right)$. The mechanism of this actuarial adjustment for the unpaid retirement benefits in the period from $R_{0}$ to $R$ is fair (or ageneutral) if the present discounted value of future retirement benefits at age $R_{0}$ is the same as at age $R .^{7}$ We now introduce a time variable $t$, such that $t=0$ at age $R_{0}$. Denoting the number of years of late retirement $r=R-R_{0}$, we define $B(0) \equiv B\left(R_{0}\right)$ and $B(r)=B(r+0) \equiv B\left(r+R_{0}\right)=B(R)$. Suppose the lifetime $T$ is certain, and $0<r<T,{ }^{8}$ and denote $\beta$ a discount rate, $0<\beta \leq 1$. The actuarial adjustment is fair if and only if

$$
\sum_{t=0}^{T-1} B(0) \beta^{t}=\sum_{t=r}^{T-1} B(r) \beta^{t},
$$

where $B(r)$ are retirement benefits not dependent on period $t .^{9}$

\footnotetext{
${ }^{6}$ We denote the lowest age at which an individual is eligible for old age benefits as the lowest retirement age. The official retirement age is the lowest retirement age specified in the law. The lowest retirement age is greater or equal to the official retirement age.

${ }^{7}$ Individual subscripts are omitted.

${ }^{8}$ Individuals may consider all known factors that enter their individual expected lifetime. In this work, we take $T$ as the expected lifetime for the total population or for a particular population group.

${ }^{9} B(r)$ is constant in real terms since it is indexed to inflation by assumption. In equation (3.1), the last period in which a person lives and receives retirement benefits is $T-1$. All the
} 
Let us introduce to the equation (3.1) the formula for retirement benefits $B(r)$ in a general form

$$
B(r)=(1+d r) b
$$

The benefit is $B(0)=b$ if retirement occurs at the age of retirement $R_{0}$. The benefit is increased in the case of retirement at an age beyond the lowest retirement age $R_{0}$ by $d r$ percent, where $d$ is the delayed retirement credit.

Substituting (3.2) in (3.1) and rearranging the terms yields

$$
\sum_{t=0}^{r-1} \beta^{t}=\sum_{t=r}^{T-1} d r \beta^{t},
$$

from which it follows that

$$
\beta^{r}+d r \beta^{r}-d r \beta^{T}-1=0
$$

or for $\beta=1$

$$
1+d r-d T=0 .
$$

The equations (3.4) and (3.5) represent implicit functions for the optimal delayed retirement credit $d$ and the optimal age of retirement $R=R_{0}+r$ given the number of years $r$ by which retirement is delayed, the discount rate $\beta$, and the lifetime $T$.

Before analyzing the equations (3.4) and (3.5), it should be noted that the equation (3.4) is a transcendental function in the number of years of late retirement $r$ and that the analytical solution for $r$ is hard to find. Therefore, we focus on finding the value of the optimal delayed retirement credit $d$. Then we analyze this function with respect to parameters $T, r$, and $\beta$.

The formula for the optimal delayed retirement credit can be easily written from equations (3.4) and (3.5) as

$$
d=\frac{1}{r} \frac{\beta^{r}-1}{\beta^{T}-\beta^{r}},
$$

and for $\beta=1$

$$
d=\frac{1}{T-r} .
$$

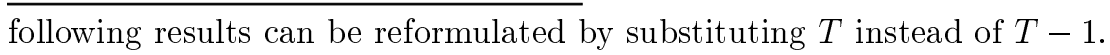


Differentiating these equations with respect to lifetime $T$ yields

$$
\frac{\partial d}{\partial T}=-\frac{1}{r} \frac{\beta^{r}-1}{\left(\beta^{T}-\beta^{r}\right)^{2}} \beta^{T} \ln \beta<0,
$$

and for $\beta=1$

$$
\frac{\partial d}{\partial T}=-\frac{1}{(T-r)^{2}}<0 .
$$

Both the equations (3.6) and (3.7) are decreasing functions in the life expectancy $T$. A longer period of collecting the adjusted benefits decreases the delayed retirement credit required.

Similarly, differentiating the equations (3.6) and (3.7) with respect to $r$ yields

$$
\frac{\partial d}{\partial r}=-\frac{1}{r^{2}} \frac{\beta^{r}-1}{\beta^{T}-\beta^{r}}+\frac{1}{r} \frac{\beta^{r} \ln \beta\left(\beta^{T}-1\right)}{\left(\beta^{T}-\beta^{r}\right)^{2}}>0,
$$

and for $\beta=1$

$$
\frac{\partial d}{\partial r}=\frac{1}{T-r}>0
$$

The proof that the function (3.6) increases in $r$ is given in the Appendix. For a particular discount rate and life expectancy, the delayed retirement credit that should be applied to compensate the pensioner for the unpaid benefits increases when a year of retirement is greater.

Differentiating the equation (3.6) with respect to the discount rate yields

$$
\frac{\partial d}{\partial \beta}=\frac{r \beta^{r-1}\left(\beta^{T}-1\right)-T \beta^{T-1}\left(\beta^{r}-1\right)}{r\left(\beta^{T}-\beta^{r}\right)^{2}}<0 .
$$

The proof that the equation (3.6) decreases in the discount rate $\beta$ in the interval from zero to one is provided in the Appendix. This supports the explanation that an increasing discount rate lowers the optimal delayed retirement credit.

\subsection{Uncertain Lifetime}

We are now able to introduce lifetime uncertainty. In this work, we use a stochastic lifetime that enters a simple utility function. The expected utility from the stochastic lifetime is compared to the utility of a particular effective time horizon. In other words, we are looking for the certainty equivalent of the stochastic lifetime. 
Suppose the stochastic length of life in the time period $t$ be $\widetilde{T}=\bar{T}+\varepsilon$, where $\bar{T}=E(T \mid T>t)$ is the conditional expected lifetime at time period $t$, and $\varepsilon$ is a random term with zero mean and finite variance $\sigma_{\varepsilon}^{2}$. Assume a twice differentiable utility $u(\widetilde{T})$ is assigned to $\widetilde{T}$. The key parameter is a risk premium $\rho(\bar{T}, \varepsilon)$ introduced as

$$
E u(\widetilde{T}) \equiv E u(\bar{T}+\varepsilon)=u(\bar{T}-\rho(\bar{T}, \varepsilon)) \equiv E\left(T_{e f f}\right)
$$

The effective lifetime $T_{\text {eff }}=\bar{T}-\rho(\bar{T}, \varepsilon)$ is a certain lifetime whose utility is the same as the expected utility of stochastic lifetime $\widetilde{T}$.

The utility of lifetime $\widetilde{T}$ can be expanded using the Taylor series as

$$
u(\bar{T}+\varepsilon) \approx u(\bar{T})+\varepsilon \frac{\partial u(\bar{T})}{\partial T}+\frac{\varepsilon^{2}}{2} \frac{\partial^{2} u(\bar{T})}{\partial T^{2}} .
$$

Applying the expected values, the equation (3.14) becomes

$$
E u(\bar{T}+\varepsilon) \approx u(\bar{T})+\frac{\sigma_{\varepsilon}^{2}}{2} \frac{\partial^{2} u(\bar{T})}{\partial T^{2}} .
$$

Assuming $\rho(\bar{T}, \varepsilon) \ll \bar{T}$, the right hand side of the equation (3.13) is

$$
u(\bar{T}-\rho(\bar{T}, \varepsilon)) \approx u(\bar{T})-\rho(\bar{T}, \varepsilon) \frac{\partial u(\bar{T})}{\partial T} .
$$

Finally, it follows from the equations (3.13), (3.15), and (3.16) that the risk premium equals

$$
\rho(\bar{T}, \varepsilon)=-\frac{\sigma_{\varepsilon}^{2}}{2} \frac{\frac{\partial^{2} u(\bar{T})}{\partial T^{2}}}{\frac{\partial u(\bar{T})}{\partial T}} .
$$

As we observe, the risk premium depends on both the first and second derivatives of the utility function defined at the mean lifetime and on the variance of the distribution of lifetime.

We are able to further analyze the equation (3.17) for a particular form of utility. We therefore introduce the constant relative risk aversion utility function

$$
u(\widetilde{T})=\frac{\widetilde{T}^{1-\gamma}}{1-\gamma}
$$


with the coefficient of risk aversion $\gamma$ being zero for risk neutral individuals, positive for those who are risk averse, and negative for risk loving individuals. ${ }^{10}$ Substituting (3.18) into (3.17) yields

$$
\rho(\bar{T}, \varepsilon)=\frac{\sigma_{\varepsilon}^{2}}{2} \frac{\gamma}{\bar{T}}
$$

The effective time horizon is then

$$
T_{e f f}=\bar{T}-\frac{\sigma_{\varepsilon}^{2}}{2} \frac{\gamma}{\bar{T}}
$$

It depends on the coefficient of risk aversion $\gamma$, on the expected lifetime $\bar{T}$, and on the variance $\sigma_{\varepsilon}^{2}$ of the distribution of stochastic lifetime. We can now write the equation (3.20) using the expected values as

$$
T_{e f f}=E(T \mid T>t)-\frac{\gamma}{2} \frac{E\left(T^{2} \mid T>t\right)-E^{2}(T \mid T>t)}{E(T \mid T>t)} .
$$

Assuming that the stochastic lifetime $\widetilde{T}$ can be described by a distribution function $f(T)$ defined from zero to the terminal age $T_{\max }$, the expected lifetime at time period $t$ is

$$
\bar{T}=\frac{\int_{t}^{T_{\max }} T f(T) d T}{\int_{t}^{T_{\max }} f(T) d T}
$$

and the variance at period $t$ equals

$$
\sigma_{\varepsilon}^{2}=\frac{\int_{t}^{T_{\max }} T^{2} f(T) d T}{\int_{t}^{T_{\max }} f(T) d T}-\left(\frac{\int_{t}^{T_{\max }} T f(T) d T}{\int_{t}^{T_{\max }} f(T) d T}\right)^{2} .
$$

We have seen that the individual risk aversion towards lifetime uncertainty can be modelled using the risk premium in the utility of lifetime. It follows from the equation (3.20) that in the case of no risk aversion $(\gamma=0)$, the effective time horizon faced by an individual equals the expected lifetime, while risk averse individuals $(\gamma>0)$ face an effective time horizon that is shorter than the expected lifetime.

\footnotetext{
${ }^{10}$ This utility function is widely used in the literature. See for example, Hurd (1989), Leung (1994), Imrohoroglu, et al. (1998).
} 


\section{Results}

In this section we find the functional form and parameters of the lifetime distribution function $f(T)$ used in the equations (3.22) and (3.23), and calculate from (3.20) the effective lifetime horizon for particular values of the coefficient of risk aversion. Then using equations (3.6) and (3.7), we calculate values of the optimal delayed retirement credit in the U.S. pension scheme for a particular range of discount rates and the number of years of late retirement. Finally, we derive values of discount rates from real interest rates.

\subsection{Calibration}

\subsubsection{Lifetime uncertainty}

Most of the life tables used in demography utilize mortality rates observed in a short period of time to construct a hypothetical cohort that faces age-specific mortality rates in the period in question. The average remaining lifetime, also called life expectancy and reported at any given age, is the average number of years remaining to be lived by those from a hypothetical cohort surviving to that age. These current life tables are presented for example in the U.S. decennial life tables for 1989 - 1991 (National Center for Health Statistics, 1997) with mortality rates calculated up to the age of 109 using data from the 1990 Census. They are published every 10 years. In other years, National Center for Health Statistics releases life tables calculated up to 99 years using the full mortality data in a given year. Recent life tables for the U.S. population in year 1997 are provided in Anderson (1999).

In order to calculate integrals in equations (3.22) and (3.23), we have to find the functional form of the probability density function $f(t)$ at a particular age $t$ and fit the parameters of this function using the data from life tables. Many studies use the Gompertz distribution, which assumes that the mortality hazard rate is an exponential function of age $t$. For example, Leung (1994) employs the parameters of the Gompertz distribution estimated in Wetterstrand (1981) from the U.S. life tables for 1969 - 1971. He uses these estimates in numerical examples of new features of the model proposed in Yaari (1965).

Thatcher, Kannisto, and Vaupel (1998) use data from 13 countries over three decades from 1960 to 1990, and apply the maximum likelihood method to estimate the parameters of six functional forms of $f(t)$ for ages from 80 to 98 . Using these estimates, they fit mortality hazard rates in the age range from 99 to 109, and 
compare the goodness of fit for these models. The choice of the break point at age 98 was chosen to avoid any errors which may result from age heaping observed in the data around age 100, or from any inaccuracies in the data above age 98 due to a low number of observations. They find that the fitted values of the Gompertz model rise more rapidly than observed death rates, and that this departure becomes noticeble after age 95 .

Since our aim is to calculate the moments of the distribution of lifetime and not to fit mortality hazard rates at advanced ages, we use the Gompertz functional form in this work. Denoting parameters $a$ and $b$ and lifetime $T$, the mortality hazard rate $\mu(T)$ becomes

$$
\mu(T)=a e^{b T} .
$$

The simplicity of the Gompertz model appears to be an advantage in computing integrals in equations (3.22) and (3.23).

Given the probability density function $f(t)$, the survivor function $S(T)$ is

$$
S(T)=1-\int_{0}^{T} f(t) d t,
$$

from which it follows that

$$
\frac{d S(T)}{d T}=-f(T)
$$

The mortality hazard rate $\mu(T)$ then equals

$$
\mu(T)=\frac{f(T)}{S(T)}=-\frac{d \ln S(T)}{d T} .
$$

By integrating the equation (4.4), we arrive at

$$
S(T)=e^{-\int_{0}^{T} \mu(t) d t}
$$

Applying the Gompertz functional form from (4.1), the probability density function follows from (4.4) and (4.5) as

$$
f(T)=a e^{b T-\int_{0}^{T} a e^{b t} d t}
$$

which can be solved as

$$
f(T)=a e^{\frac{a}{b}+b T-\frac{a}{b} e^{b T}} .
$$


In order to calculate the expected lifetime and its variance from equations (3.22) and (3.23) using equation (4.7), we should estimate parameters $a$ and $b$. For this purpose we rewrite equation (4.1) as

$$
\ln \mu(T)=\ln a+b T+\varepsilon,
$$

where $\varepsilon$ is a disturbance term distributed with zero mean and constant variance. We estimate the parameters of equation (4.8) using the method of least squares on the data from life tables. ${ }^{11}$

Table A.1 provides estimates of $a$ and $b$ with standard errors for 1990 as well as the expected lifetime $\bar{T}$ and variance $\sigma_{\varepsilon}^{2}$ at the age 65 calculated from equations (3.22) and (3.23). The parameters of $a$ and $b$ were estimated for mortality hazard rates from ages 65 to 109 using data from National Center for Health Statistics (1997). Since the aim is to have a good fit after age 65, we substracted the value of 65 from the actual age, so that the period in question is from 0 to 44 . This transformation is necessary in order to avoid integrating in the equation (4.6) over the period for which the paremeters $a$ and $b$ were not estimated. In other words, we assume that the mortality hazard rates are zero for ages under $65 .{ }^{12}$ The expected lifetime and the variance in (3.22) and (3.23) were calculated at age 65 by integrating over the period from 0 to 44 , which corresponds to ages from 65 to 109. In the last row of the table we show the value of the expected lifetime $E(T)$ from the U.S. decennial life tables published in National Center for Health Statistics (1997). As we can see, the expected lifetimes calculated from the equation (3.22) are in accordance with the tabulated values.

Using data from Anderson (1999), similar results are reported for year 1997 in Table A.2. Integrals from (3.22) and (3.23) were calculated over the age interval from 65 to 109 transformed to the range from 0 to 44 . However, the fitted parameters $a$ and $b$ were estimated for ages from 65 to 99 , because the life tables in Anderson (1999) do not provide mortality hazard rates after age 99. As we again observe, the fit of parameters $a$ and $b$ is good, and calculated values of expected lifetime $\bar{T}$ are in accordance with the tabulated values of life expectancy $E(T)$ at age 65 .

\footnotetext{
${ }^{11}$ The disturbance term $\varepsilon$ is autocorrelated in the equation (4.8) since non-linearities are neglected in this functional form. Since the Gompertz model departs significantly from the observed death rates only at advanced ages, the use of the least squares is justified.

${ }^{12}$ Integrals $\int f(T) d T$ given in denominators of the equations (3.22) and (3.23) equal 0.9994 for the total population, 0.9998 for males, and 0.9992 for females. These values are very close to unity, and the assumption that the mortality hazard rates are zero for ages before age 65 is therefore justified.
} 
As we have seen, the range of ages over which fitted parameters were estimated is not the same in 1990 and 1997. In order to examine how that change affects the size of expected lifetime $\bar{T}$ and variance $\sigma_{\varepsilon}^{2}$, we reestimated the equation (4.8) for the range of ages from 65 to 99 using the data from 1990. The results are provided in Table A.3. Integrals given in (3.22) and (3.23) were calculated over the age interval from 65 to 109 transformed to 0 to 44 . We can see that expected lifetimes do not change significantly when the range of fit is shorter, but the variances are smaller than in Table A.1. ${ }^{13}$

\subsubsection{Risk aversion}

In order to proceed with numerical solutions, we must choose values for the coefficient of risk aversion. An important contribution to this topic was made by Hurd (1989). He estimates an extended life cycle model of consumption in which utility depends on the path of consumption and bequests. Using the same utility function as in equation (3.18), he obtains the value of 0.729 with standard error 0.091 using the nonlinear least squares on the panel data from the Retirement History Survey. Then he reestimates his model by nonlinear 2SLS with the result of 1.12 with standard error 0.074. As Hurd (1989) points out, his estimates are much smaller than those assumed in the previous literature. His estimates are used in Leung (1994) to complete the set of values chosen at 0.1, 0.5, 1 and 3 in a numerical analysis. Imrohoroglu (1998) employs values of 1.5 and 3 in his simulations.

Based on this experience, we use Hurd's (1989) estimate of 1.12 as a benchmark of our model. In order to examine how the variation in the coefficient of risk aversion affects the effective time horizon, we also provide results for the other Hurd's (1989) estimate of 0.729, and for the value of 2 .

\subsection{Optimal delayed retirement credit}

In this subsection we provide the numerical results of the theoretical section with parameters found in the previous subsection. First, we compute the effective time

\footnotetext{
${ }^{13}$ As we mentioned, the Gompertz method provides fitted values of the logarithm of the mortality hazard rate higher than those observed at advanced ages. This implies that a shorter range of fit delivers a higher estimate of $b$ in the equation (4.8). The probability density function $f(T)$ given in (4.7) is narrower than for a longer range of fit, which implies that the variance is naturally lower. Later we will return to this point and investigate how the change in the variance affects our results.
} 
horizon from equation (3.20). Regarding the expected lifetime, we do not use the calculated values $\bar{T}$ from equation (3.22), but employ the values from life tables given in the last row of Tables A.1 and A.2. The variance $\sigma_{\varepsilon}^{2}$ used is from Tables A.1 and A.2.

Table A.4 summarizes the results for the total population, males, and females for the years 1990 and 1997. The calculations were performed for values of the coefficient of risk aversion of $0.729,1.12$, and 2. The case of $\gamma=0$ represents no risk aversion, and values reported in this row help to demonstrate how the effective time horizon shortens with increasing risk aversion. In 1997, the effective time horizon is 17.7 years for the total population, but only 15.1 years when the most often cited estimate of the coefficient of risk aversion is taken into account. In 1997, the time horizon falls from 15.9 to 13.2 years for males and from 19.2 to 16.8 years for females. Table A.4 also demonstrates how the expected lifetime has changed between 1990 and $1997 .^{14}$

With the results from Table A.4, we are able to calculate from equations (3.6) and (3.7) the optimal delayed retirement credit for particular discount rates and years of late retirement. Table A.5 provides results for the case of no risk aversion $(\gamma=0)$, and for risk aversion $(\gamma=1.12)$ for the total population in 1997. In the case of no risk aversion, the optimal delayed retirement credit at age 65 is $6.0 \%$ for unity discount rate if retirement is delayed by 1 year, while it is $6.4 \%$ and $6.8 \%$ when retirement is delayed by 2 or 3 years. When the discount rate is lower than unity, the optimal delayed retirement credit increases. When an individual delays retirement by 1 year, the optimal value changes from $6.0 \%$ to $6.5 \%$ while the discount rate decreases from 1 to 0.99 , and to $7.1 \%$ for $\beta=0.98$. This significant impact is also noticeable for other values of years of late retirement, indicating that the optimal delayed retirement credit given in the equation (3.6) is sensitive to the variation in the discount rate. In order to illustrate this finding, Figure A.1 shows that the first derivative of the delayed retirement credit with respect to the discount rate declines as the discount rate decreases. Moreover, the first

\footnotetext{
${ }^{14}$ Now we may go back to the point from the previous footnote and analyze how the change in the variance affects results. We calculated values of the effective time horizon using the variance $\sigma_{\varepsilon}^{2}$ and expected lifetime $E(T)$ from Table A.3 for 1990. For the coefficients of risk aversion $0.729,1.12$, and 2 , the effective time horizon is $15.5,14.6$ and 12.5 years in the case of the total population, 13.3, 12.4 and 10.2 years for males, and 17.4, 16.6 and 14.7 years for females. By comparing these values with the results for the year 1990 reported in Table A.4, we may conclude that the difference is negligible except the case of the coefficient of risk aversion $\gamma=2$ when the difference is 0.3 years. This indicates that fitting the functional form of $f(T)$ over the shorter age interval in 1997 is sufficient for the purpose of this work.
} 
derivative is lower for more years of late retirement.

When one accounts for risk aversion, the optimal delayed retirement credit increases from $6.0 \%$ to $7.1 \%$ when the discount rate is unity and retirement is delayed by 1 year. The ratio of the optimal credit in the cases with and without risk aversion is provided in Table A.6. The ratio for unity discount rate and 1 year late retirement is 1.184 , but increases to 1.198 for 2 years, and even to 1.257 for 5 years late retirement. This implies that risk aversion has a more significant impact on the size of the optimal delayed credit the later an individual retires, although in the case of other values of discount rates, the effect of risk aversion diminishes. Thus, the ratio drops from 1.184 to 1.118 , and 1.070 for discount rates $1,0.95$, and 0.90 . This effect is also observed for other values of years of late retirement.

Similar results for the optimal delayed retirement credit and for the effect of risk aversion are provided for males in Tables A.7 and A.8, and for females in Tables A.9 and A.10. Since the effective time horizon is longer for females than for males as observed in Table A.4, the optimal delayed retirement credit is, not surprisingly, lower for females than for males for all values of discount rate and years of late retirement. As the results from Tables A.8 and A.10 indicate, risk aversion has a less significant impact on delayed retirement credit for females than for males.

Regarding the discount rates used to calculate the present discounted value of future retirement benefits, we are able to shed some light on their magnitude using the U.S. real interest rates. Figure A. $2^{15}$ shows real interest rates on 1-year Treasury Bills and Long-Term U.S. Government Securities in the period from 1986 to 1997 . These interest rates range from $2 \%$ to $5 \%$ with the exception of the period from 1991 to 1993 when real interest rates from T-bills dropped to zero. In 1997, real interest rates on deposits were between $3 \%$ and $4.5 \%$. This implies that relevant discount rates were between 0.96 and 0.97 in 1997. As we observe in Figure A.3 ${ }^{16}$ real interest rates on borrowing were observed mostly between $4 \%$ and $6.5 \%$ during the period 1986 - 1997, and between $5 \%$ and $6.5 \%$ in 1997 . These correspond to the values of the discount rate from 0.94 to 0.95 for 1997 .

As Tables A.5, A.7, and A.9 show, the optimal delayed retirement credit at age 65 is $6.0 \%$ with no discounting and 1 year late retirement for the total population

\footnotetext{
${ }^{15}$ Source: Own calculations; data from Federal Reserve Board of Governors and U.S. Department of Labor, Bureau of Labor Statistics.

${ }^{16}$ Source: Own calculations; data from Federal Reserve Board of Governors and U.S. Department of Labor, Bureau of Labor Statistics.
} 
in 1997. However when discounting is accounted for, the optimal delayed credit is between $7.8 \%$ and $9.9 \%$. In the case of risk aversion, the delayed credit is $7.1 \%$ for no discounting, and between $8.9 \%$ and $11.0 \%$ for discount rates derived from real interest rates in 1997 . For males, the optimal delayed retirement credit is $6.7 \%$ for no discounting, and between $8.5 \%$ and $10.6 \%$ for discount rates from 0.94 to 0.97 . In the case of risk aversion, delayed credits are $8.2 \%$, and between $10.0 \%$ and $12.0 \%$. The optimal values for females are $5.5 \%, 7.3 \%$ and $9.4 \%$ for no risk aversion, and $6.3 \%, 8.1 \%$ and $10.2 \%$ for risk averse females. All these results derived for 1 year late retirement and 1997 are repeated in Table A.11.

We may conclude that discounting has an important impact on the size of the optimal delayed retirement credit, since, when discounting is properly measured, the optimal delayed retirement credit may be at least $25 \%$ greater than in the case of no discounting. Moreover, risk aversion towards uncertain lifetime increases values of the optimal delayed retirement credit by $15 \%$ to $25 \%$.

The results reported in Table A.11 were derived for age 65 and 1 year late retirement. Since the optimal value of the delayed retirement credit increases with the number of years of late retirement, see equations (3.10) and (3.11), the results in Table A.11 are minimum values required in the actuarial adjustment scheme.

In order to explain the U.S. "retirement puzzle" at age 62 (see Section 2), we must calculate the optimal delayed retirement credit at age 62 that provides an incentive not to retire before age 65. Table A.12 summarizes the optimal delayed credit in the case of 3 years late retirement in year $1997 .{ }^{17}$ Since the actuarial increase is $8 \%$ between ages 62 and 65 in the U.S. pension scheme, we may conclude that when there is no discounting, the adjustment is fair between ages 62 and 65. The only exceptions are risk averse males for which the actuarial increase is not sufficient. However when discounting is considered in the calculations, the actuarial increase is only fair for some risk neutral females.

Finally, we should assess the sensitivity of the results to alternative values of the coefficient of risk aversion. For this purpose we tabulate values of the optimal delayed credit at age 65 for the coefficient of risk aversion 0 (risk neutrality), 0.729, 1.12, and 2. The results for 1 year late retirement are presented in Table A.13 for the total population, in Table A.14 for males, and in Table A.15 for females. ${ }^{18}$

\footnotetext{
${ }^{17}$ These results are almost identical to the results in Table A.11 for age 65 and 1 year late retirement. We should note that the optimal delayed credit decreases with the life expectancy, but increases with the number of years of late retirement.

${ }^{18}$ Results for $\gamma=1.12$ are repeated from Tables A.5, A.7, and A.9.
} 
In the case of the total population, for example, the delayed credit changes from $6.7 \%$ to $7.1 \%$ when the coefficient of risk aversion increases from 0.729 to 1.12 and the discount rate is unity. A similar slight increase in the optimal delayed retirement credit is observed for males and females. However when the coefficient of risk aversion increases from 1.12 to 2 , the delayed credit rises from $7.1 \%$ to $8.3 \%$ for the total population, as seen in Table A.13, and a similar significant increase is observed for males and females in Tables A.14 and A.15. This suggests that risk aversion should be properly measured in order to obtain reliable results for the optimal delayed retirement credit.

\section{Policy Implications and Concluding Remarks}

We have learned that the formula for the optimal delayed retirement credit is sensitive to the number of years of late retirement and to the life expectancy at the particular age of retirement. The effect of the number of years of late retirement is neglected when it is short enough with respect to the life expectancy.

Regarding the effect of the life expectancy on the optimal delayed retirement credit, the key problem is that the life expectancy is different for males and females. This problem is even more significant in economies where the official retirement age is not the same for males and females. This is for example the case in the United Kingdom and in the transition economies in Central and Eastern Europe. In order to eliminate the age-dependency of retirement decisions of individuals, the optimal delayed retirement credit should be different for males and females.

The formula for the delayed retirement credit is also sensitive to the discount rate used to calculate the present discounted value of future retirement benefits. Our results indicate that in economies with positive real interest rates, the optimal delayed retirement credit differs significantly from that which has been implemented under the assumption of no discounting.

We may conclude that since the delayed retirement credit is institutionally determined, it can fairly reward unpaid benefits only when late retirement is short enough with respect to the life expectancy and when the discount rate is close to one. Only in this case is the optimal value of the delayed credit approximately stable. This implies that policies related to late retirement and the earnings test can be effective only in a short period beyond the official retirement age.

We modelled lifetime uncertainty as the certainty equivalent to the stochastic lifetime. We demonstrated that risk aversion towards uncertain lifetime reduces 
the effective time horizon. Risk aversion has in this sense the same effect as a reduced lifetime. In order to account for the lifetime uncertainty, the optimal delayed retirement credit should be higher for risk averse individuals than for those who are risk neutral.

In the empirical part of the paper, we found parameters of the lifetime probability distribution function, and using appropriate coefficients of risk aversion, we calculated the effective time horizon for the U.S. total population, males, and females at age 65 in 1997. Then we calculated the optimal delayed retirement credit for the same groups of population at age 65 in year 1997. From U.S. real interest rates, we found that discount rates were likely observed between 0.94 and 0.97 in year 1997. In the case of risk aversion and 1 year late retirement at age 65 in year 1997, we came to conclusion that the optimal values for the delayed credit are $7.1 \%$ for the total population, $8.2 \%$ for males, and $6.3 \%$ for females when discounting is neglected. However, when discount rates from real interest rates are implemented, the optimal values for the delayed retirement credit are between $8.9 \%$ and $11.0 \%$ for the total population, between $10.0 \%$ and $12.0 \%$ for males, and between $8.1 \%$ and $10.2 \%$ for females. We should keep in mind that these are the optimal values that should be implemented in the actuarial adjusment scheme in order to provide an incentive at age 65 to delay retirement by 1 year in year 1997. The most important finding is that optimal values for the delayed retirement credit are at least $25 \%$ greater than in the case of no discounting. Comparing these results with those for risk neutrality, we may also conclude that risk aversion increases the optimal delayed retirement credit by $15-25 \%$.

We found that discounting and risk aversion may explain "the retirement puzzle" which appears between ages 62 and 65 in the U.S. pension scheme. In order to encourage postponing retirement by 3 years at age 62 , the optimal delayed retirement credit should be set between $8.7 \%$ and $11.2 \%$ for males, and between $7.4-10.0 \%$ for females in the case of risk neutrality based on 1997 data. When risk aversion is taken into account, the optimal values are between $10.3-12.8 \%$ for males, and between $8.2-10.8 \%$ for females. The $8 \%$ delayed retirement credit that is currently applied in the U.S. pension scheme between ages 62 and 65 does not compensate individuals deciding to delay retirement from age 62 to age 65 for their lost retirement benefits.

We obtained our results for discount rates equal to or lower than unity. The equation (3.6) indicates however that the optimal delayed retirement credit is defined even for values of discount rates greater than unity. This implies that our results could easily be extended to discount rates greater than unity. 
The results of this work are sensitive to how discount rates and risk aversion are measured. Our experience indicates that it may be difficult to find the optimal parameters of the pension scheme that would provide an incentive to retire later. Moreover, the decisions of older workers to retire and to undertake post-retirement work are affected by other factors that are beyond the scope of this study. An important incentive to retire later may be induced when the replacement rate between average net earnings in the years preceding retirement and retirement benefits is lower than unity. The indexation of old-age pensions to inflation as well as the volatility in real interest rates may also have significant effects on workers' decisions to retire. 


\section{References}

[1] Anderson, Robert N. (1999), "United States Life Tables, 1997," National Statistics Reports, vol. 47 no. 28, Hyattsville, Maryland: National Center for Health Statistics.

[2] Blau, David M. (1994), "Labor Force Dynamics of Older Men," Econometrica 62(1): 117-156.

[3] Burkhauser, Richard V. and Joseph F. Quinn (1997), "Implementing ProWork Policies for Older Americans in the Twenty-First Century," Syracuse University, Maxwell School Policy Brief.

[4] Burtless, Gary and Robert A. Moffitt (1985), "The Joint Choice of Retirement Age and Postretirement Hours of Work," Journal of Labor Economics 3(2): 209-236.

[5] Hurd, Michael (1989), "Mortality Risk and Bequests," Econometrica 57(4): 779-813.

[6] Hurd, Michael (1996), "The Effect of Labor Market Rigidities on the Labor Force Behavior of Older Workers," in David A. Wise ed., Advances in the Economics of Aging, NBER, Chicago: The University of Chicago Press.

[7] Imrohoroglu, Ayse, Selahattin Imrohoroglu, and Douglas H. Joines (1998), "The Effect of Tax-Favored Retirement Accounts on Capital Accumulation," The American Economic Review 88(4): 749-768.

[8] Kahn, James A. (1988), "Social Security, Liquidity, and Early Retirement," Journal of Public Economics 35: 97-117.

[9] Kocherlakota, Narayana R. (1990), "On the 'Discount' Factor in Growth Economies," Journal of Monetary Economics 25: 43-47.

[10] Leung, Siu Fai (1994), "Notes and comments: Uncertain Lifetime, the Theory of the Consumer, and the Life Cycle Hypothesis," Econometrica 62(5): 12331239 .

[11] National Center for Health Statistics (1997), U.S.Decennial Life Tables for1989-1991, vol. 1 no. 2, Hyattsville, Maryland. 
[12] Peracchi, Franco and Finis Welch (1994), "Trends in Labor Force Transitions of Older Men and Women," Journal of Labor Economics 12(2): 210-242.

[13] Reimers, Cordelia and Marjorie Honig (1993), "The Perceived Budget Constraint under Social Security: Evidence from Reentry Behavior," Journal of Labor Economics 11(1): 184-207.

[14] Rust, John and Christopher Phelan (1997), "How Social Security and Medicare Affect Retirement Behavior in a World of Incomplete Markets," Econometrica 65(4): 781-831.

[15] Schrooten Mechthild, Timothy M. Smeeding and Gert G. Wagner (1998), "Old-Age Security Reforms in Central-Eastern Europe: The Cases of Czech Republic, Slovakia, Hungary and Poland," Luxembourg Income Study Working Paper No. 189.

[16] Smeeding, Timothy M. and Joseph F. Quinn (1997), "Cross-National Patterns of Labor Force Withdrawal," Luxembourg Income Study Working Paper No. 170.

[17] Stock, James H. and David A. Wise (1990), "Pensions, the Option Value of Work, and Retirement," Econometrica 58(5): 1151-1180.

[18] Thatcher, A. P., V. Kannisto and J. W. Vaupel (1998), The Force of Mortality at Ages 80 to 120, Odense: Odense University Press.

[19] Wetterstrand, W. (1981), "Parametric Models for Life Insurance Mortality Data: Gompertz's Law Over Time," Transactions of the Society of Actuaries 33: $159-179$.

[20] Whitehouse, Edward (1990), "The Abolition of the Pensions 'Earnings Rule'," Fiscal Studies 11(3), 55-70.

[21] World Bank (1994), Averting the Old Age Crisis: Policies to Protect the Old and Promote Growth, Policy Research Report Series. Oxford and New York: Oxford University Press for the World Bank.

[22] Yaari, Menahem E. (1965), "Uncertain Lifetime, Life Insurance, and the Theory of the Consumer," Review of Economic Studies 32(2): 137-150. 


\section{A. Appendix}

Theorem A.1. It follows from (3.6) that

$$
\frac{\partial d}{\partial r}=-\frac{1}{r^{2}} \frac{\beta^{r}-1}{\beta^{T}-\beta^{r}}+\frac{1}{r} \frac{\beta^{r}\left(\beta^{T}-1\right) \ln \beta}{\left(\beta^{T}-\beta^{r}\right)^{2}}>0,
$$

where $d$ is the delayed retirement credit, $\beta$ is the discount rate, such that $0<\beta<$ $1, r$ is the number of years of late retirement, and $T$ is the life expectancy, such that $0<r<T$.

Proof. Let us start by proving the Theorem for $r \rightarrow 0$. Using the Taylor series, we can write $\beta^{r}$ for small $r$ as $\beta^{r} \approx 1+r \ln \beta$. Substituting $\beta^{r}$ into the equation yields

$$
\begin{aligned}
\frac{\partial d}{\partial r} & \approx-\frac{1}{r^{2}} \frac{r \ln \beta}{\beta^{T}-1-r \ln \beta}+\frac{1}{r} \frac{(1+r \ln \beta)\left(\beta^{T}-1\right) \ln \beta}{\left(\beta^{T}-1-r \ln \beta\right)^{2}}= \\
& =\frac{-\ln \beta\left(\beta^{T}-1\right)+r(\ln \beta)^{2}+\ln \beta\left(\beta^{T}-1\right)+r(\ln \beta)^{2}\left(\beta^{T}-1\right)}{r\left(\beta^{T}-1-r \ln \beta\right)^{2}}= \\
& =\frac{\beta^{T}(\ln \beta)^{2}}{\left(\beta^{T}-1-r \ln \beta\right)^{2}}>0 .
\end{aligned}
$$

Going back to the Theorem, $\frac{\partial d}{\partial r}>0$ if and only if

$$
\frac{1}{r} \frac{\beta^{r}\left(\beta^{T}-1\right) \ln \beta}{\left(\beta^{T}-\beta^{r}\right)^{2}}>\frac{1}{r^{2}} \frac{\beta^{r}-1}{\beta^{T}-\beta^{r}} .
$$

Rearranging the terms in this inequality gives

$$
\begin{aligned}
r \beta^{r} \ln \beta\left(\beta^{T}-1\right) & >\left(\beta^{r}-1\right)\left(\beta^{T}-\beta^{r}\right), \\
r \beta^{r} \beta^{T} \ln \beta-r \beta^{r} \ln \beta & >\beta^{r} \beta^{T}-\beta^{r} \beta^{r}-\beta^{T}+\beta^{r}, \\
r \beta^{T} \ln \beta-r \ln \beta+\beta^{T-r}+\beta^{r} & >\beta^{T}+1 .
\end{aligned}
$$

Denote as $L(r)$ the left hand side and $R$ the right hand side of the last inequality. Differentiating $L(r)$ with respect to $r$ supplies

$$
\begin{aligned}
\frac{\partial L(r)}{\partial r} & =\beta^{T} \ln \beta-\ln \beta-\beta^{T-r} \ln \beta+\beta^{r} \ln \beta= \\
& =\ln \beta\left(\left(\beta^{T}-\beta^{T-r}\right)+\left(\beta^{r}-1\right)\right)>0 .
\end{aligned}
$$


We have shown that $\frac{\partial L(r)}{\partial r}>0$ since $\ln \beta<0$ and both terms in the parentheses are negative. Keeping in mind that $R$ is not a function in $r$, we conclude that if $L(r)>R$ for some $r$, then $L(r)>R$ for all $r^{\prime}$, such that $r^{\prime}>r$. But we know that $L(r)>R$ for $r \rightarrow 0$ which completes the proof of the Theorem.

Theorem A.2. It follows from (3.6) that

$$
\frac{\partial d}{\partial \beta}=\frac{r \beta^{r-1}\left(\beta^{T}-1\right)-T \beta^{T-1}\left(\beta^{r}-1\right)}{r\left(\beta^{T}-\beta^{r}\right)^{2}}<0,
$$

where $d$ is the delayed retirement credit, $\beta$ is the discount rate, such that $0<\beta<$ $1, r$ is the number of years of late retirement, and $T$ is the life expectancy, such that $0<r<T$.

Proof. The first derivative of the delayed retirement credit with respect to the discount rate is negative if and only if

$$
r \beta^{r-1}\left(\beta^{T}-1\right)<T \beta^{T-1}\left(\beta^{r}-1\right)
$$

or rearranging the terms

$$
\frac{r \beta^{r-1}}{\beta^{r}-1}<\frac{T \beta^{T-1}}{\beta^{T}-1}
$$

Since $T>r$, it is necessary to show that a function

$$
f(x)=\frac{x \beta^{x-1}}{\beta^{x}-1}
$$

is increasing in the parameter $x$. Differentiating $f(x)$ with respect to $x$ yields

$$
\begin{aligned}
\frac{\partial f(x)}{\partial x} & =\frac{\left(\beta^{x-1}+x \beta^{x-1} \ln \beta\right)\left(\beta^{x}-1\right)-x \beta^{x-1} \beta^{x} \ln \beta}{\left(\beta^{x}-1\right)^{2}}= \\
& =\frac{\beta^{x-1}\left(\beta^{x}-1\right)-x \beta^{x-1} \ln \beta}{\left(\beta^{x}-1\right)^{2}} .
\end{aligned}
$$

The nominator in the last equation is positive if and only if

$$
\beta^{x-1}\left(\beta^{x}-1\right)>x \beta^{x-1} \ln \beta,
$$

or

$$
\beta^{x}-1-x \ln \beta=\beta^{x}-1-\ln \beta^{x}>0 .
$$


Since the inequality becomes equality for $x=0$ and since $x>0$, we should prove that the last inequality is increasing in $x$. Differentiating with respect to $x$ supplies

$$
\beta^{x} \ln \beta-\ln \beta=\left(\beta^{x}-1\right) \ln \beta>0
$$

since $\beta^{x}<1$ and $\ln \beta<0$. 


\begin{tabular}{|c|c|c|c|}
\hline & Total population & Males & Females \\
\hline $\ln a$ & $-3.943(0.023)$ & $-3.605(0.029)$ & $-4.261(0.029)$ \\
\hline$b$ & $0.0782(0.0009)$ & $0.0717(0.0011)$ & $0.0863(0.0011)$ \\
\hline$R^{2}$ & 0.9944 & 0.9896 & 0.9926 \\
\hline$a$ & 0.0194 & 0.0272 & 0.0141 \\
\hline $\bar{T}$ & 17.2 & 15.0 & 19.0 \\
\hline$\sigma_{\varepsilon}^{2}$ & 87.0 & 78.7 & 89.4 \\
\hline$E(T)$ & 17.3 & 15.1 & 19.0 \\
\hline
\end{tabular}

Table A.1: Fitted parameters, age 65 - 109, year 1990

\begin{tabular}{|c|c|c|c|}
\hline & Total population & Males & Females \\
\hline $\ln a$ & $-4.104(0.010)$ & $-3.826(0.015)$ & $-4.402(0.013)$ \\
\hline$b$ & $0.0868(0.0005)$ & $0.0820(0.0007)$ & $0.0956(0.0006)$ \\
\hline$R^{2}$ & 0.9988 & 0.9972 & 0.9985 \\
\hline$a$ & 0.0165 & 0.0218 & 0.0123 \\
\hline $\bar{T}$ & 17.6 & 15.9 & 19.0 \\
\hline$\sigma_{\varepsilon}^{2}$ & 82.2 & 76.2 & 81.9 \\
\hline$E(T)$ & 17.7 & 15.9 & 19.2 \\
\hline
\end{tabular}

Table A.2: Fitted parameters, age 65 - 99, year 1997

\begin{tabular}{|c|c|c|c|}
\hline & Total population & Males & Females \\
\hline $\ln a$ & $-4.017(0.008)$ & $-3.694(0.014)$ & $-4.353(0.012)$ \\
\hline$b$ & $0.0839(0.0004)$ & $0.0787(0.0007)$ & $0.0934(0.0006)$ \\
\hline$R^{2}$ & 0.9992 & 0.9975 & 0.9986 \\
\hline$a$ & 0.0180 & 0.0249 & 0.0129 \\
\hline $\bar{T}$ & 17.2 & 15.1 & 18.9 \\
\hline$\sigma_{\varepsilon}^{2}$ & 82.3 & 74.1 & 83.1 \\
\hline$E(T)$ & 17.3 & 15.1 & 19.0 \\
\hline
\end{tabular}

Table A.3: Fitted parameters, age 65 - 99, year 1990 


\begin{tabular}{|c|c|c|c|c|c|c|}
\hline & \multicolumn{2}{|c|}{ Total population } & \multicolumn{2}{c|}{ Males } & \multicolumn{2}{c|}{ Females } \\
\hline$\gamma$ & $\mathbf{1 9 9 0}$ & $\mathbf{1 9 9 7}$ & $\mathbf{1 9 9 0}$ & $\mathbf{1 9 9 7}$ & $\mathbf{1 9 9 0}$ & $\mathbf{1 9 9 7}$ \\
\hline 0 & 17.3 & 17.7 & 15.1 & 15.9 & 19.0 & 19.2 \\
\hline 0.729 & 15.4 & 16.0 & 13.2 & 14.1 & 17.3 & 17.6 \\
\hline 1.12 & 14.5 & 15.1 & 12.2 & 13.2 & 16.4 & 16.8 \\
\hline 2 & 12.2 & 13.0 & 9.9 & 11.1 & 14.3 & 14.9 \\
\hline
\end{tabular}

Table A.4: The effective time horizon

\begin{tabular}{|c|c|c|c|c|c|c|c|c|c|c|}
\hline & \multicolumn{9}{|c|}{ Number of years of late retirement (r) } \\
\hline & \multicolumn{2}{|c|}{$\mathbf{1}$} & \multicolumn{2}{|c|}{$\mathbf{2}$} & \multicolumn{2}{|c|}{$\mathbf{3}$} & \multicolumn{2}{c|}{$\mathbf{4}$} & \multicolumn{2}{c|}{ 5 } \\
\hline$\beta$ & noRA & RA & noRA & $\mathbf{R A}$ & noRA & RA & noRA & RA & noRA & RA \\
\hline $\mathbf{1 . 0 0}$ & 0.060 & 0.071 & 0.064 & 0.076 & 0.068 & 0.083 & 0.073 & 0.090 & 0.079 & 0.099 \\
\hline $\mathbf{0 . 9 9}$ & 0.065 & 0.076 & 0.070 & 0.082 & 0.074 & 0.089 & 0.080 & 0.097 & 0.086 & 0.107 \\
\hline $\mathbf{0 . 9 8}$ & 0.071 & 0.082 & 0.076 & 0.089 & 0.081 & 0.096 & 0.087 & 0.105 & 0.094 & 0.115 \\
\hline $\mathbf{0 . 9 7}$ & 0.078 & 0.089 & 0.083 & 0.095 & 0.088 & 0.103 & 0.095 & 0.113 & 0.103 & 0.124 \\
\hline $\mathbf{0 . 9 6}$ & 0.084 & 0.095 & 0.090 & 0.103 & 0.096 & 0.111 & 0.104 & 0.122 & 0.112 & 0.134 \\
\hline $\mathbf{0 . 9 5}$ & 0.091 & 0.102 & 0.098 & 0.110 & 0.105 & 0.120 & 0.113 & 0.131 & 0.122 & 0.145 \\
\hline $\mathbf{0 . 9 4}$ & 0.099 & 0.110 & 0.106 & 0.119 & 0.114 & 0.129 & 0.123 & 0.141 & 0.133 & 0.156 \\
\hline $\mathbf{0 . 9 3}$ & 0.107 & 0.118 & 0.115 & 0.127 & 0.124 & 0.139 & 0.134 & 0.152 & 0.145 & 0.168 \\
\hline $\mathbf{0 . 9 2}$ & 0.116 & 0.126 & 0.124 & 0.137 & 0.134 & 0.149 & 0.145 & 0.164 & 0.158 & 0.182 \\
\hline $\mathbf{0 . 9 1}$ & 0.125 & 0.134 & 0.134 & 0.146 & 0.145 & 0.160 & 0.158 & 0.177 & 0.173 & 0.196 \\
\hline $\mathbf{0 . 9 0}$ & 0.134 & 0.144 & 0.145 & 0.157 & 0.157 & 0.172 & 0.172 & 0.190 & 0.188 & 0.212 \\
\hline $\mathbf{0 . 8 9}$ & 0.144 & 0.153 & 0.156 & 0.168 & 0.170 & 0.185 & 0.186 & 0.205 & 0.205 & 0.229 \\
\hline $\mathbf{0 . 8 8}$ & 0.155 & 0.163 & 0.168 & 0.179 & 0.184 & 0.198 & 0.202 & 0.220 & 0.223 & 0.247 \\
\hline $\mathbf{0 . 8 7}$ & 0.166 & 0.174 & 0.181 & 0.191 & 0.198 & 0.212 & 0.219 & 0.237 & 0.243 & 0.267 \\
\hline $\mathbf{0 . 8 6}$ & 0.177 & 0.185 & 0.194 & 0.204 & 0.214 & 0.227 & 0.237 & 0.255 & 0.264 & 0.288 \\
\hline $\mathbf{0 . 8 5}$ & 0.189 & 0.196 & 0.208 & 0.218 & 0.231 & 0.244 & 0.257 & 0.274 & 0.287 & 0.311 \\
\hline $\mathbf{0 . 8 4}$ & 0.201 & 0.208 & 0.223 & 0.232 & 0.248 & 0.261 & 0.278 & 0.295 & 0.312 & 0.336 \\
\hline $\mathbf{0 . 8 3}$ & 0.214 & 0.221 & 0.239 & 0.247 & 0.267 & 0.279 & 0.300 & 0.317 & 0.340 & 0.363 \\
\hline $\mathbf{0 . 8 2}$ & 0.228 & 0.234 & 0.255 & 0.263 & 0.287 & 0.298 & 0.324 & 0.341 & 0.369 & 0.392 \\
\hline $\mathbf{0 . 8 1}$ & 0.242 & 0.247 & 0.272 & 0.280 & 0.308 & 0.319 & 0.350 & 0.366 & 0.401 & 0.424 \\
\hline $\mathbf{0 . 8 0}$ & 0.256 & 0.261 & 0.290 & 0.297 & 0.330 & 0.341 & 0.378 & 0.393 & 0.436 & 0.458 \\
\hline
\end{tabular}

Table A.5: Optimal delayed retirement credit at age 65, risk aversion 0 and 1.12, U.S. total population, 1997 


\begin{tabular}{|c|c|c|c|c|c|}
\hline & \multicolumn{5}{|c|}{$\mathbf{r}$} \\
\hline$\beta$ & $\mathbf{1}$ & $\mathbf{2}$ & $\mathbf{3}$ & $\mathbf{4}$ & $\mathbf{5}$ \\
\hline $\mathbf{1 . 0 0}$ & 1.184 & 1.198 & 1.215 & 1.234 & 1.257 \\
\hline $\mathbf{0 . 9 9}$ & 1.169 & 1.183 & 1.199 & 1.219 & 1.241 \\
\hline $\mathbf{0 . 9 8}$ & 1.155 & 1.169 & 1.185 & 1.204 & 1.226 \\
\hline $\mathbf{0 . 9 7}$ & 1.142 & 1.155 & 1.171 & 1.189 & 1.211 \\
\hline $\mathbf{0 . 9 6}$ & 1.129 & 1.142 & 1.158 & 1.176 & 1.197 \\
\hline $\mathbf{0 . 9 5}$ & 1.118 & 1.130 & 1.145 & 1.163 & 1.184 \\
\hline $\mathbf{0 . 9 4}$ & 1.107 & 1.119 & 1.133 & 1.151 & 1.171 \\
\hline $\mathbf{0 . 9 3}$ & 1.096 & 1.108 & 1.122 & 1.139 & 1.159 \\
\hline $\mathbf{0 . 9 2}$ & 1.087 & 1.098 & 1.112 & 1.128 & 1.148 \\
\hline $\mathbf{0 . 9 1}$ & 1.078 & 1.089 & 1.102 & 1.118 & 1.137 \\
\hline $\mathbf{0 . 9 0}$ & 1.070 & 1.081 & 1.093 & 1.108 & 1.126 \\
\hline $\mathbf{0 . 8 9}$ & 1.063 & 1.073 & 1.084 & 1.099 & 1.116 \\
\hline $\mathbf{0 . 8 8}$ & 1.056 & 1.065 & 1.077 & 1.090 & 1.107 \\
\hline $\mathbf{0 . 8 7}$ & 1.050 & 1.058 & 1.069 & 1.082 & 1.099 \\
\hline $\mathbf{0 . 8 6}$ & 1.044 & 1.052 & 1.062 & 1.075 & 1.090 \\
\hline $\mathbf{0 . 8 5}$ & 1.039 & 1.047 & 1.056 & 1.068 & 1.083 \\
\hline $\mathbf{0 . 8 4}$ & 1.034 & 1.041 & 1.050 & 1.062 & 1.076 \\
\hline $\mathbf{0 . 8 3}$ & 1.030 & 1.037 & 1.045 & 1.056 & 1.069 \\
\hline $\mathbf{0 . 8 2}$ & 1.026 & 1.032 & 1.040 & 1.050 & 1.063 \\
\hline $\mathbf{0 . 8 1}$ & 1.023 & 1.028 & 1.036 & 1.045 & 1.057 \\
\hline $\mathbf{0 . 8 0}$ & 1.020 & 1.025 & 1.032 & 1.040 & 1.052 \\
\hline
\end{tabular}

Table A.6: Ratio of risk averse to non-risk averse optimal delayed retirement credit at age 65 , U.S. total population, 1997 


\begin{tabular}{|c|c|c|c|c|c|c|c|c|c|c|}
\hline & \multicolumn{9}{|c|}{ Number of years of late retirement (r) } \\
\hline & \multicolumn{2}{|c|}{$\mathbf{1}$} & \multicolumn{2}{|c|}{$\mathbf{2}$} & \multicolumn{2}{|c|}{$\mathbf{3}$} & \multicolumn{2}{|c|}{$\mathbf{4}$} & \multicolumn{2}{c|}{$\mathbf{5}$} \\
\hline$\beta$ & noRA & RA & noRA & RA & noRA & RA & noRA & RA & noRA & RA \\
\hline $\mathbf{1 . 0 0}$ & 0.067 & 0.082 & 0.072 & 0.089 & 0.078 & 0.098 & 0.084 & 0.109 & 0.092 & 0.122 \\
\hline $\mathbf{0 . 9 9}$ & 0.073 & 0.088 & 0.078 & 0.095 & 0.084 & 0.105 & 0.091 & 0.116 & 0.099 & 0.130 \\
\hline $\mathbf{0 . 9 8}$ & 0.079 & 0.093 & 0.084 & 0.102 & 0.091 & 0.112 & 0.098 & 0.124 & 0.108 & 0.139 \\
\hline $\mathbf{0 . 9 7}$ & 0.085 & 0.100 & 0.091 & 0.109 & 0.098 & 0.119 & 0.107 & 0.133 & 0.116 & 0.149 \\
\hline $\mathbf{0 . 9 6}$ & 0.091 & 0.106 & 0.098 & 0.116 & 0.106 & 0.128 & 0.115 & 0.142 & 0.126 & 0.159 \\
\hline $\mathbf{0 . 9 5}$ & 0.099 & 0.113 & 0.106 & 0.124 & 0.115 & 0.136 & 0.125 & 0.151 & 0.137 & 0.170 \\
\hline $\mathbf{0 . 9 4}$ & 0.106 & 0.120 & 0.114 & 0.132 & 0.124 & 0.145 & 0.135 & 0.162 & 0.148 & 0.182 \\
\hline $\mathbf{0 . 9 3}$ & 0.114 & 0.128 & 0.123 & 0.140 & 0.133 & 0.155 & 0.146 & 0.173 & 0.160 & 0.195 \\
\hline $\mathbf{0 . 9 2}$ & 0.122 & 0.136 & 0.132 & 0.149 & 0.144 & 0.165 & 0.157 & 0.185 & 0.173 & 0.209 \\
\hline $\mathbf{0 . 9 1}$ & 0.131 & 0.145 & 0.142 & 0.159 & 0.155 & 0.176 & 0.170 & 0.198 & 0.188 & 0.224 \\
\hline $\mathbf{0 . 9 0}$ & 0.140 & 0.154 & 0.153 & 0.169 & 0.167 & 0.188 & 0.183 & 0.211 & 0.203 & 0.240 \\
\hline $\mathbf{0 . 8 9}$ & 0.150 & 0.163 & 0.164 & 0.180 & 0.179 & 0.201 & 0.198 & 0.226 & 0.220 & 0.257 \\
\hline $\mathbf{0 . 8 8}$ & 0.160 & 0.173 & 0.175 & 0.191 & 0.193 & 0.214 & 0.214 & 0.241 & 0.238 & 0.276 \\
\hline $\mathbf{0 . 8 7}$ & 0.171 & 0.183 & 0.188 & 0.203 & 0.207 & 0.228 & 0.230 & 0.258 & 0.258 & 0.296 \\
\hline $\mathbf{0 . 8 6}$ & 0.182 & 0.194 & 0.201 & 0.216 & 0.223 & 0.243 & 0.248 & 0.276 & 0.279 & 0.317 \\
\hline $\mathbf{0 . 8 5}$ & 0.194 & 0.205 & 0.214 & 0.229 & 0.239 & 0.259 & 0.268 & 0.295 & 0.302 & 0.341 \\
\hline $\mathbf{0 . 8 4}$ & 0.206 & 0.216 & 0.229 & 0.243 & 0.256 & 0.276 & 0.288 & 0.316 & 0.327 & 0.366 \\
\hline $\mathbf{0 . 8 3}$ & 0.218 & 0.228 & 0.244 & 0.258 & 0.274 & 0.294 & 0.311 & 0.338 & 0.354 & 0.393 \\
\hline $\mathbf{0 . 8 2}$ & 0.232 & 0.241 & 0.260 & 0.273 & 0.294 & 0.313 & 0.334 & 0.361 & 0.384 & 0.422 \\
\hline $\mathbf{0 . 8 1}$ & 0.245 & 0.254 & 0.277 & 0.289 & 0.315 & 0.333 & 0.360 & 0.386 & 0.415 & 0.454 \\
\hline $\mathbf{0 . 8 0}$ & 0.259 & 0.268 & 0.294 & 0.306 & 0.337 & 0.354 & 0.388 & 0.413 & 0.450 & 0.489 \\
\hline
\end{tabular}

Table A.7: Optimal delayed retirement credit at age 65, risk aversion 0 and 1.12 , U.S. males, 1997 


\begin{tabular}{|c|c|c|c|c|c|}
\hline & \multicolumn{5}{|c|}{$\mathbf{r}$} \\
\hline$\beta$ & $\mathbf{1}$ & $\mathbf{2}$ & $\mathbf{3}$ & $\mathbf{4}$ & $\mathbf{5}$ \\
\hline $\mathbf{1 . 0 0}$ & 1.221 & 1.241 & 1.265 & 1.293 & 1.329 \\
\hline $\mathbf{0 . 9 9}$ & 1.205 & 1.225 & 1.248 & 1.276 & 1.312 \\
\hline $\mathbf{0 . 9 8}$ & 1.190 & 1.209 & 1.232 & 1.260 & 1.295 \\
\hline $\mathbf{0 . 9 7}$ & 1.175 & 1.194 & 1.217 & 1.244 & 1.278 \\
\hline $\mathbf{0 . 9 6}$ & 1.162 & 1.180 & 1.202 & 1.229 & 1.262 \\
\hline $\mathbf{0 . 9 5}$ & 1.149 & 1.167 & 1.188 & 1.214 & 1.247 \\
\hline $\mathbf{0 . 9 4}$ & 1.136 & 1.154 & 1.175 & 1.201 & 1.233 \\
\hline $\mathbf{0 . 9 3}$ & 1.125 & 1.142 & 1.162 & 1.187 & 1.219 \\
\hline $\mathbf{0 . 9 2}$ & 1.114 & 1.131 & 1.150 & 1.175 & 1.205 \\
\hline $\mathbf{0 . 9 1}$ & 1.104 & 1.120 & 1.139 & 1.163 & 1.193 \\
\hline $\mathbf{0 . 9 0}$ & 1.095 & 1.110 & 1.128 & 1.151 & 1.180 \\
\hline $\mathbf{0 . 8 9}$ & 1.086 & 1.100 & 1.118 & 1.140 & 1.169 \\
\hline $\mathbf{0 . 8 8}$ & 1.078 & 1.092 & 1.109 & 1.130 & 1.158 \\
\hline $\mathbf{0 . 8 7}$ & 1.070 & 1.083 & 1.100 & 1.120 & 1.147 \\
\hline $\mathbf{0 . 8 6}$ & 1.063 & 1.076 & 1.091 & 1.111 & 1.137 \\
\hline $\mathbf{0 . 8 5}$ & 1.057 & 1.069 & 1.084 & 1.103 & 1.127 \\
\hline $\mathbf{0 . 8 4}$ & 1.051 & 1.062 & 1.076 & 1.095 & 1.118 \\
\hline $\mathbf{0 . 8 3}$ & 1.045 & 1.056 & 1.069 & 1.087 & 1.110 \\
\hline $\mathbf{0 . 8 2}$ & 1.040 & 1.050 & 1.063 & 1.080 & 1.101 \\
\hline $\mathbf{0 . 8 1}$ & 1.036 & 1.045 & 1.057 & 1.073 & 1.094 \\
\hline $\mathbf{0 . 8 0}$ & 1.032 & 1.041 & 1.052 & 1.067 & 1.086 \\
\hline
\end{tabular}

Table A.8: Ratio of risk averse to non-risk averse optimal delayed retirement credit at age 65, U.S. males, 1997 


\begin{tabular}{|c|c|c|c|c|c|c|c|c|c|c|}
\hline & \multicolumn{10}{|c|}{ Number of years of late retirement $(r)$} \\
\hline & \multicolumn{2}{|c|}{1} & \multicolumn{2}{|c|}{2} & \multicolumn{2}{|c|}{3} & \multicolumn{2}{|c|}{4} & \multicolumn{2}{|c|}{5} \\
\hline$\beta$ & noRA & $\mathbf{R A}$ & noRA & RA & noRA & RA & noRA & RA & noRA & RA \\
\hline 1.00 & 0.055 & 0.063 & 0.058 & 0.068 & 0.062 & 0.072 & 0.066 & 0.078 & 0.070 & 0.085 \\
\hline 0.99 & 0.060 & 0.069 & 0.064 & 0.073 & 0.068 & 0.079 & 0.072 & 0.085 & 0.077 & 0.092 \\
\hline 0.98 & 0.066 & 0.075 & 0.070 & $\overline{0.080}$ & 0.075 & 0.086 & 0.080 & 0.092 & 0.082 & 0.100 \\
\hline 0.97 & 0.073 & 0.081 & 0.077 & 0.087 & 0.082 & 0.093 & 0.087 & 0.100 & $\overline{0.094}$ & 0.109 \\
\hline 0.96 & $\overline{0.079}$ & 0.088 & 0.084 & 0.094 & 0.090 & 0.101 & 0.096 & 0.109 & 0.103 & 0.118 \\
\hline 0.95 & & & 0.092 & 0.102 & & 0.109 & 0.105 & 0.118 & 0.113 & 0.129 \\
\hline 0.94 & 0.094 & 0.102 & 0.101 & 0.110 & 0.107 & 0.118 & 0.115 & 0.128 & 0.124 & 0.140 \\
\hline 0.93 & 03 & 110 & 0.110 & 0.119 & 0.117 & 0.128 & 0.126 & 0.139 & 0.136 & 0.152 \\
\hline 0.92 & 0.111 & $\overline{0.119}$ & 0.119 & 0.128 & 0.128 & 0.139 & 0.138 & 0.151 & 0.149 & 0.165 \\
\hline 0.91 & 121 & 128 & 0.129 & 0.138 & 0.139 & 0.150 & 0.150 & 0.163 & 0.163 & 0.179 \\
\hline 0.90 & 0.130 & 0.137 & 0.140 & 0.149 & 0.151 & 0.162 & 0.164 & 0.177 & 0.179 & 0.195 \\
\hline 0.89 & 0.140 & 0.147 & 0.152 & 0.160 & 0.164 & 0.174 & 0.179 & 0.192 & 0.196 & $\overline{0.212}$ \\
\hline .88 & 151 & 157 & 0.164 & 0.172 & 0.178 & 0.188 & 0.195 & 0.207 & 0.214 & 0.230 \\
\hline 0.87 & 0.162 & 0.168 & 0.177 & 0.184 & 0.193 & 0.202 & 0.212 & 0.224 & 0.234 & $\overline{0.250}$ \\
\hline 0.86 & 0.174 & 0.179 & 0.190 & 0.197 & 0.209 & 0.218 & 0.230 & 0.242 & 0.255 & 0.271 \\
\hline 0.85 & 0.186 & 0.191 & 0.205 & 0.211 & 0.226 & 0.234 & 0.250 & 0.262 & 0.278 & 0.294 \\
\hline 0.84 & 0.199 & 0.203 & 0.220 & 0.226 & 0.244 & 0.252 & 0.271 & 0.282 & 0.304 & 0.319 \\
\hline 0.83 & 0.212 & 0.216 & 0.235 & 0.241 & 0.262 & 0.270 & 0.294 & 0.305 & 0.331 & 0.346 \\
\hline 0.82 & 0.226 & 0.229 & 0.252 & 0.257 & 0.283 & 0.290 & 0.319 & 0.329 & 0.361 & 0.376 \\
\hline 0.81 & 0.240 & 0.243 & 0.269 & 0.274 & 0.304 & 0.311 & 0.345 & 0.355 & 0.393 & 0.407 \\
\hline 0.80 & 0.254 & 0.258 & 0.287 & $\overline{0.292}$ & 0.326 & 0.333 & 0.373 & 0.382 & 0.428 & 0.442 \\
\hline
\end{tabular}

Table A.9: Optimal delayed retirement credit at age 65, risk aversion 0 and 1.12, U.S. females, 1997 


\begin{tabular}{|c|c|c|c|c|c|}
\hline & \multicolumn{5}{|c|}{$\mathbf{r}$} \\
\hline$\beta$ & $\mathbf{1}$ & $\mathbf{2}$ & $\mathbf{3}$ & $\mathbf{4}$ & $\mathbf{5}$ \\
\hline $\mathbf{1 . 0 0}$ & 1.152 & 1.162 & 1.174 & 1.188 & 1.203 \\
\hline $\mathbf{0 . 9 9}$ & 1.138 & 1.149 & 1.160 & 1.174 & 1.189 \\
\hline $\mathbf{0 . 9 8}$ & 1.126 & 1.136 & 1.147 & 1.160 & 1.176 \\
\hline $\mathbf{0 . 9 7}$ & 1.114 & 1.124 & 1.135 & 1.148 & 1.163 \\
\hline $\mathbf{0 . 9 6}$ & 1.103 & 1.112 & 1.123 & 1.136 & 1.151 \\
\hline $\mathbf{0 . 9 5}$ & 1.093 & 1.102 & 1.112 & 1.125 & 1.139 \\
\hline $\mathbf{0 . 9 4}$ & 1.083 & 1.092 & 1.102 & 1.114 & 1.128 \\
\hline $\mathbf{0 . 9 3}$ & 1.074 & 1.083 & 1.093 & 1.104 & 1.118 \\
\hline $\mathbf{0 . 9 2}$ & 1.066 & 1.074 & 1.084 & 1.095 & 1.108 \\
\hline $\mathbf{0 . 9 1}$ & 1.059 & 1.067 & 1.076 & 1.086 & 1.099 \\
\hline $\mathbf{0 . 9 0}$ & 1.052 & 1.059 & 1.068 & 1.078 & 1.091 \\
\hline $\mathbf{0 . 8 9}$ & 1.046 & 1.053 & 1.061 & 1.071 & 1.083 \\
\hline $\mathbf{0 . 8 8}$ & 1.040 & 1.047 & 1.055 & 1.064 & 1.075 \\
\hline $\mathbf{0 . 8 7}$ & 1.035 & 1.041 & 1.049 & 1.057 & 1.068 \\
\hline $\mathbf{0 . 8 6}$ & 1.031 & 1.037 & 1.043 & 1.052 & 1.062 \\
\hline $\mathbf{0 . 8 5}$ & 1.027 & 1.032 & 1.038 & 1.046 & 1.056 \\
\hline $\mathbf{0 . 8 4}$ & 1.023 & 1.028 & 1.034 & 1.041 & 1.050 \\
\hline $\mathbf{0 . 8 3}$ & 1.020 & 1.024 & 1.030 & 1.037 & 1.045 \\
\hline $\mathbf{0 . 8 2}$ & 1.017 & 1.021 & 1.026 & 1.032 & 1.040 \\
\hline $\mathbf{0 . 8 1}$ & 1.015 & 1.018 & 1.023 & 1.029 & 1.036 \\
\hline $\mathbf{0 . 8 0}$ & 1.013 & 1.016 & 1.020 & 1.025 & 1.032 \\
\hline
\end{tabular}

Table A.10: Ratio of risk averse to non-risk averse optimal delayed retirement credit at age 65, U.S. females, 1997

\begin{tabular}{|c|c|c|c|c|c|c|}
\hline & \multicolumn{2}{|c|}{ Total population } & \multicolumn{2}{c|}{ Males } & \multicolumn{2}{c|}{ Females } \\
\hline & noRA & RA & noRA & RA & noRA & RA \\
\hline No discounting & $6.0 \%$ & $7.1 \%$ & $6.7 \%$ & $8.2 \%$ & $5.5 \%$ & $6.3 \%$ \\
\hline Discounting & $7.8-9.9 \%$ & $8.9-11.0 \%$ & $8.5-10.6 \%$ & $10.0-12.0 \%$ & $7.3-9.4 \%$ & $8.1-10.2 \%$ \\
\hline
\end{tabular}

Table A.11: Optimal delayed retirement credit at age 65, risk aversion 0 and 1.12 , 1 year late retirement, 1997 


\begin{tabular}{|c|c|c|c|c|c|c|}
\hline & \multicolumn{2}{|c|}{ Total population } & \multicolumn{2}{c|}{ Males } & \multicolumn{2}{c|}{ Females } \\
\hline & noRA & RA & noRA & RA & noRA & RA \\
\hline No discounting & $5.9 \%$ & $7.0 \%$ & $6.7 \%$ & $8.2 \%$ & $5.4 \%$ & $6.2 \%$ \\
\hline Discounting & $7.9-10.5 \%$ & $9.1-11.6 \%$ & $8.7-11.2 \%$ & $10.3-12.8 \%$ & $7.4-10.0 \%$ & $8.2-10.8 \%$ \\
\hline
\end{tabular}

Table A.12: Optimal delayed retirement credit at age 62, risk aversion 0 and 1.12, 3 years late retirement, 1997

\begin{tabular}{|c|c|c|c|c|}
\hline$\beta$ & $\gamma=0$ & $\gamma=0.729$ & $\gamma=1.12$ & $\gamma=2$ \\
\hline 1 & 0.060 & 0.067 & 0.071 & 0.083 \\
\hline 0.99 & 0.065 & 0.072 & 0.076 & 0.089 \\
\hline 0.98 & 0.071 & 0.078 & 0.082 & 0.095 \\
\hline 0.97 & 0.078 & 0.084 & 0.089 & 0.101 \\
\hline 0.96 & 0.084 & 0.091 & 0.095 & 0.108 \\
\hline 0.95 & 0.091 & 0.098 & 0.102 & 0.115 \\
\hline 0.94 & 0.099 & 0.106 & 0.110 & 0.122 \\
\hline 0.93 & 0.107 & 0.113 & 0.118 & 0.129 \\
\hline 0.92 & 0.116 & 0.122 & 0.126 & 0.138 \\
\hline 0.91 & 0.125 & 0.131 & 0.134 & 0.146 \\
\hline 0.90 & 0.134 & 0.140 & 0.144 & 0.155 \\
\hline
\end{tabular}

Table A.13: The effect of risk aversion on the optimal delayed retirement credit at age 65, 1 year late retirement, total population 1997 


\begin{tabular}{|c|c|c|c|c|}
\hline$\beta$ & $\gamma=0$ & $\gamma=0.729$ & $\gamma=1.12$ & $\gamma=2$ \\
\hline 1 & 0.067 & 0.076 & 0.082 & 0.099 \\
\hline 0.99 & 0.073 & 0.082 & 0.088 & 0.105 \\
\hline 0.98 & 0.079 & 0.088 & 0.093 & 0.111 \\
\hline 0.97 & 0.085 & 0.094 & 0.100 & 0.117 \\
\hline 0.96 & 0.091 & 0.101 & 0.106 & 0.123 \\
\hline 0.95 & 0.099 & 0.108 & 0.113 & 0.130 \\
\hline 0.94 & 0.106 & 0.115 & 0.120 & 0.137 \\
\hline 0.93 & 0.114 & 0.123 & 0.128 & 0.145 \\
\hline 0.92 & 0.122 & 0.131 & 0.136 & 0.153 \\
\hline 0.91 & 0.131 & 0.139 & 0.145 & 0.161 \\
\hline 0.90 & 0.140 & 0.148 & 0.154 & 0.170 \\
\hline
\end{tabular}

Table A.14: The effect of risk aversion on the optimal delayed retirement credit at age 65, 1 year late retirement, males 1997

\begin{tabular}{|c|c|c|c|c|}
\hline$\beta$ & $\gamma=0$ & $\gamma=0.729$ & $\gamma=1.12$ & $\gamma=2$ \\
\hline 1 & 0.055 & 0.060 & 0.063 & 0.072 \\
\hline 0.99 & 0.060 & 0.066 & 0.069 & 0.077 \\
\hline 0.98 & 0.066 & 0.072 & 0.075 & 0.083 \\
\hline 0.97 & 0.073 & 0.078 & 0.081 & 0.090 \\
\hline 0.96 & 0.079 & 0.085 & 0.088 & 0.096 \\
\hline 0.95 & 0.087 & 0.092 & 0.095 & 0.103 \\
\hline 0.94 & 0.094 & 0.099 & 0.102 & 0.111 \\
\hline 0.93 & 0.103 & 0.107 & 0.110 & 0.118 \\
\hline 0.92 & 0.111 & 0.116 & 0.119 & 0.127 \\
\hline 0.91 & 0.121 & 0.125 & 0.128 & 0.135 \\
\hline 0.90 & 0.130 & 0.135 & 0.137 & 0.145 \\
\hline
\end{tabular}

Table A.15: The effect of risk aversion on the optimal delayed retirement credit at age 65, 1 year late retirement, females 1997 


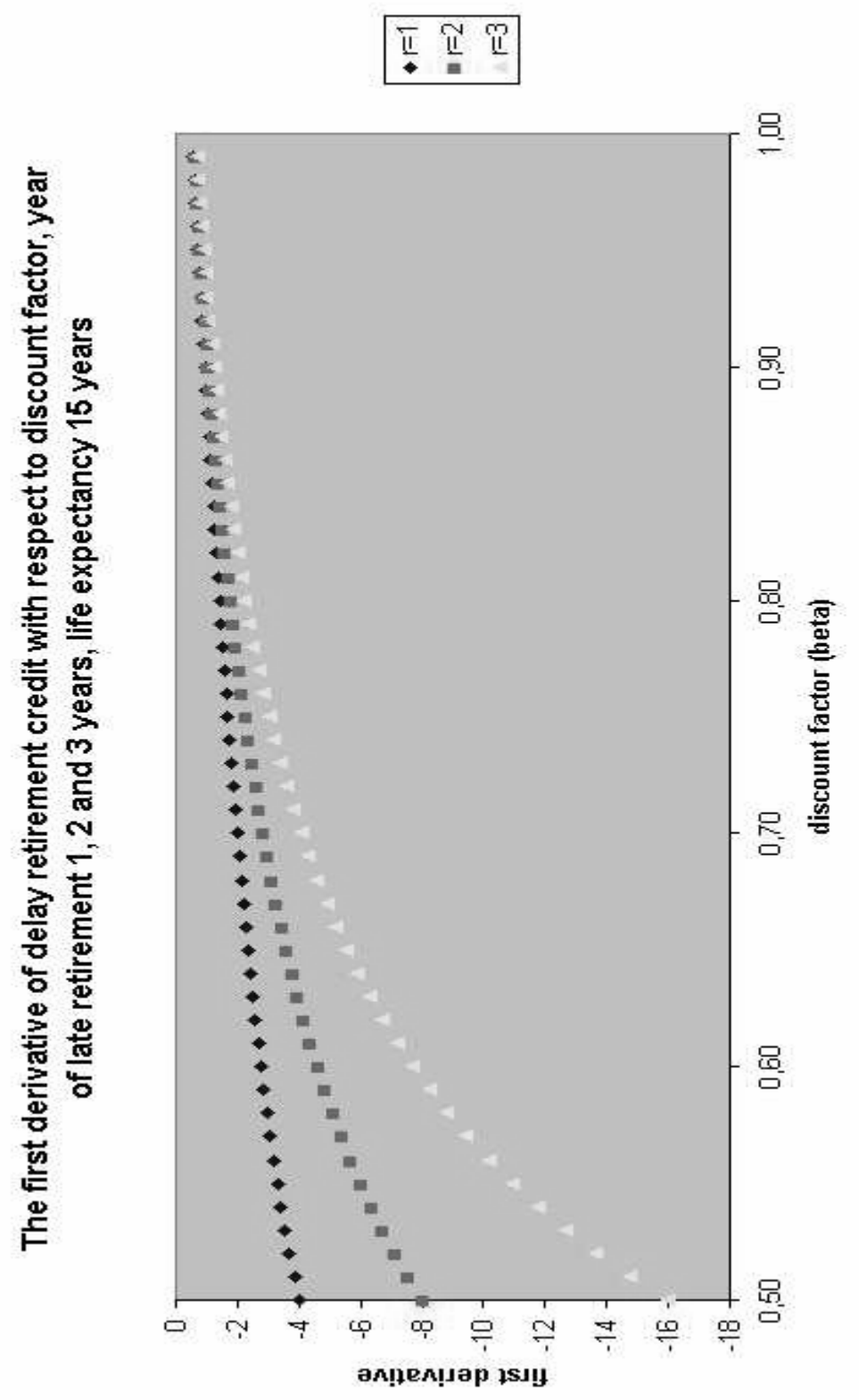

Figure A.1: First derivatives of the delayed retirement credit 


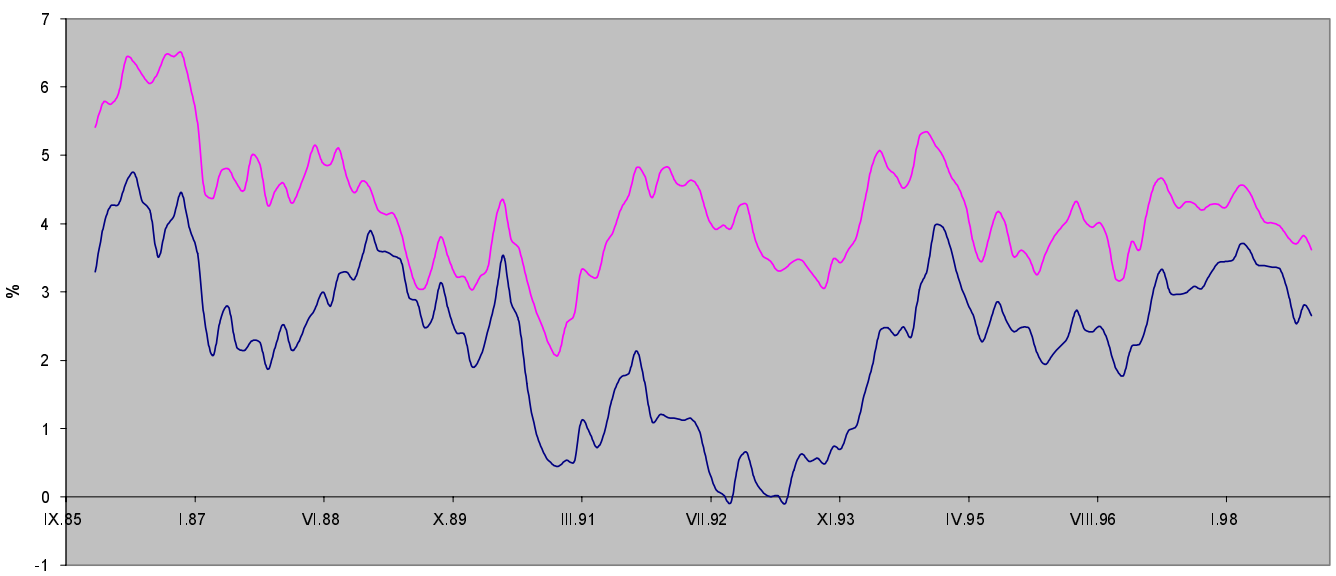

-1-year Treasury Bill Rate —- Long-Term U.S. Government Securities

Figure A.2: Real interest rates on deposits in the United States

Real interest rates on loans in the United States

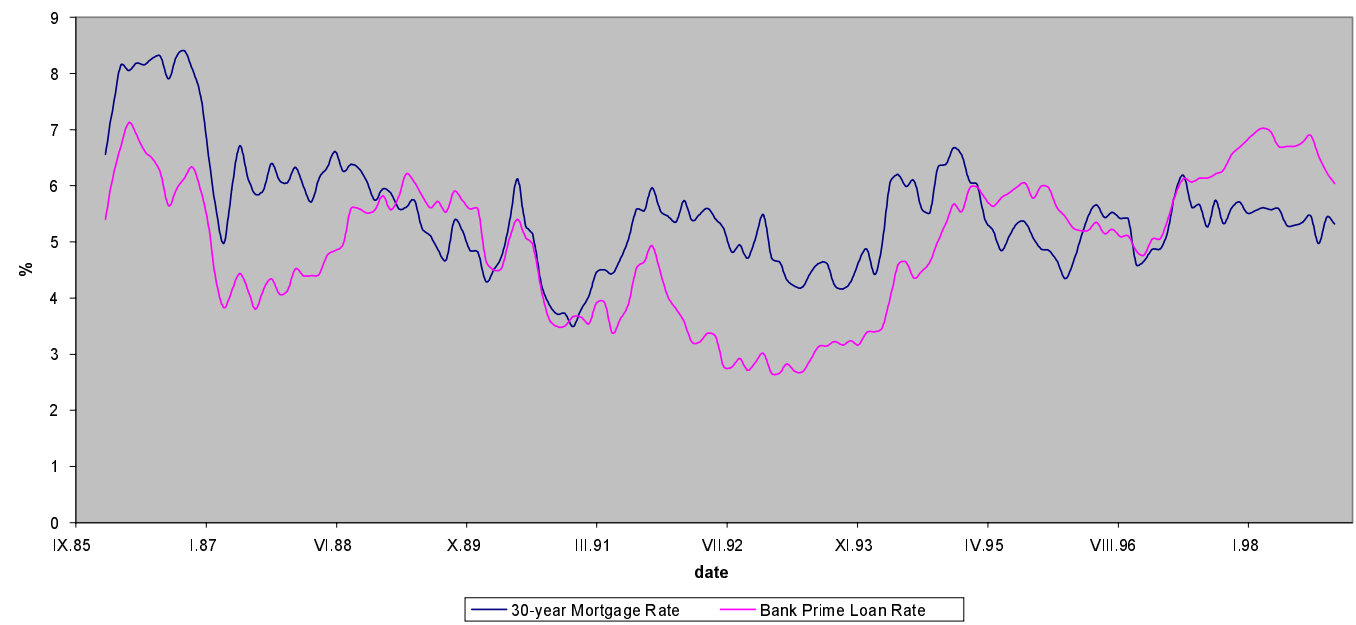

Figure A.3: Real interest rates on loans in the United States 